\title{
Monitoring hydration in lime-metakaolin composites using electrochemical impedance spectroscopy and nuclear magnetic resonance spectroscopy ${ }^{\dagger}$
}

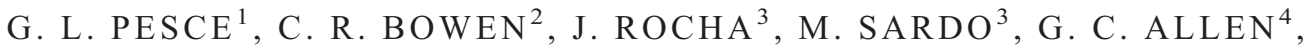 \\ P. J. WALKER ${ }^{1}$, G. DENUAULT ${ }^{5}$, M. SERRAPEDE ${ }^{5}$ AND R. J. BALL ${ }^{1, *}$ \\ $\dagger$ Invited lecture given at the Cement and Concrete 2013 Conference in Portsmouth, September 2013 \\ ${ }^{I}$ Department of Architecture and Civil Engineering, University of Bath, Bath UK, ${ }^{2}$ Department of Mechanical \\ Engineering, University of Bath, Bath, UK, ${ }^{3}$ Department of Chemistry, CICECO, University of Aveiro, Aveiro, \\ Portugal, ${ }^{4}$ Interface Analysis Centre, University of Bristol, Bristol, UK, and ${ }^{5}$ Department of Chemistry, \\ University of Southampton, Southampton, UK
}

(Received 20 December 2013; revised 12 May 2014; Editor: George Christidis)

\begin{abstract}
This paper describes a study of the hydraulic reactions between metakaolin (MK) and air lime using electrochemical impedance spectroscopy (EIS) and nuclear magnetic resonance spectroscopy (NMR). Tests were carried out at 20,25 and $30^{\circ} \mathrm{C}$ on lime-MK pastes with 10:1 w/w ratio. Tests over 28 days allowed identification of relevant changes in the EIS signals and characterization of pastes using thermal analysis (TGA/DSC), scanning electron microscopy (SEM), mercury intrusion porosimetry (MIP) and uni-axial compressive tests. Tests over shorter periods of time (up to $42 \mathrm{~h}$ ) allowed more detailed studies of the hydraulic phases formed at the very beginning of the reactions.

Results of thermal analyses demonstrate formation of hydraulic compounds such as $\mathrm{CSH}, \mathrm{C}_{4} \mathrm{AH}_{13}$ and $\mathrm{C}_{3} \mathrm{ASH}_{6}$ and show their evolution over time. MIP analysis demonstrates changes in pore size distribution related to the formation and trasformation of hydraulic phases. Variations of impedance response with time are shown to be associated with reaction kinetics. Changes in the NMR signal within the first $42 \mathrm{~h}$ of reaction are shown to be associated with the dissolution of calcium hydroxide in the pore solution. Overall, this paper demonstrates the importance of NMR in the study of hydraulic reactions in lime based materials and the ability of EIS to detect the formation of hydraulic compounds and the end of the calcium hydroxide dissolution process.
\end{abstract}

KeYwords: lime, metakaolin, impedance spectroscopy, nuclear magnetic resonance spectroscopy.

Metakaolin (MK) has been used for centuries as a hydraulic additive in the construction industry (Pesce, 2006; Pesce \& Ricci, 2008). Currently it

* E-mail: R.J.Ball@bath.ac.uk

DOI: 10.1180 /claymin.2014.049.3.01 is mainly used for the production of high performance, high strength and lightweight concrete, in fibre-cement products or in glass fibre reinforced concrete. In addition to these products, MK is also used in smaller productions used in the conservation of built heritage (such as "Albaria allettamento": a lime-based material produced by BASF Construction Chemicals Italy) and in several 
research projects aimed to develop new ecosustainable lime-based materials (e.g. Morsy et al., 2012).

Cold mixtures of air lime and MK are important binders for conservation, restoration and new build applications. Elasticity, vapour permeability and the eco-sustainability of the mortars produced with these binders are the most important attributes that can be ascribed to the precipitation of calcium silicate and aluminate hydrate and, in the long term, to carbonation (Ball et al., 2012).

Despite these interesting properties, however, little work to date has been carried out on the evolution of hydraulic phases in pure MK-lime mixtures. The existing scientific literature, in fact, is mainly focused on MK-cement blends but unfortunately these systems cannot be easily used in the study of lime-based materials containing air lime. Differences in chemistry of cement and lime are the main limitations. In cement, mineralogical phases such as tricalcium aluminate $\left(\mathrm{C}_{3} \mathrm{~A}\right)$ or tricalcium silicate $\left(\mathrm{C}_{3} \mathrm{~S}\right)$ that do not exist in pastes of air lime and MK, form specific hydraulic compounds which create highly complex systems that do not allow an easy transmission of knowledge between materials with different binder phases (Frias et al., 2013).

\section{B A C K GROUND}

Despite these limitations, however, some general knowledge has already been agreed among researchers interested in lime-based building materials. It is agreed, for instance, that the times at which different hydration products are formed, their stability and the mineralogical transformations that occur with the hydration time depend on several factors such as MK-lime ratio, temperature and presence of activators (Cabrera \& Rojas, 2001). Cabrera and Rojas detected Calcium Silicate Hydrate (CSH) formed as hydration products after six hours in a $1: 1$ lime-MK paste cured at $60^{\circ} \mathrm{C}$. After $12 \mathrm{~h}$ other hydration products such as $\mathrm{C}_{2} \mathrm{ASH}_{8}$ (stratlingite) and $\mathrm{C}_{4} \mathrm{AH}_{13}$ (tetra calcium aluminate hydrate) were also clearly detected. Hydrogarnet $\mathrm{C}_{3} \mathrm{ASH}_{6}$ was detected after $21 \mathrm{~h}$ hydration suggesting that this compound can be produced not only by transformation of metastable phases but also by a direct reaction between MK and lime (Cabrera \& Rojas, 2001).

Until a few years ago results like these were mainly obtained using traditional techniques such as thermo-gravimetry, differential thermal analyses (TG/DTA) and X-ray diffraction analysis (XRD; Frias et al., 2013). Most recently, however, an insight into the hydraulic reaction between air lime and MK was provided by less traditional techniques including Raman spectroscopy (Martinez-Ramirez \& Frias, 2011) and Nuclear Magnetic Resonance spectroscopy (NMR; Frias et al., 2013). In 2011, in particular, Martinez-Ramirez and Frias analysed the hydration compounds of a $1: 1 \mathrm{w} / \mathrm{w} \mathrm{Ca}(\mathrm{OH})_{2}: \mathrm{MK}$ blend with a $2: 37$ water solid ratio, cured at $60^{\circ} \mathrm{C}$ in plastic airtight containers. After two hours from the mix, the typical Raman bands of portlandite and a small signal of carbonate were detected, probably due to carbonation during handling and storage of the sample. Three more bands were attributed to $\mathrm{O}-$ $\mathrm{H}$ stretching vibrations of water molecules (one of these was attributed to unreacted MK) and a small band was attributed to $\mathrm{Si}-\mathrm{O}-\mathrm{Si}$ symmetrical bending vibration in $\mathrm{CSH}$ gel (Martinez-Ramirez \& Frias, 2011). After six hours of curing, the portlandite bands were still detected together with the first signal due to the $\mathrm{OH}$ bonded into $\mathrm{C}_{4} \mathrm{AH}_{13}$ phase and in calcium aluminum hydrate phases $\left(\mathrm{C}_{4} \mathrm{AH}_{19}, \mathrm{C}_{2} \mathrm{ASH}_{8}\right)$. The broadness of this signal suggested presence of different $\mathrm{AlO}_{4}^{5-}$ environments. At $21 \mathrm{~h}$, portlandite, stratlingite and calcium aluminum hydrate $\left(\mathrm{C}_{2} \mathrm{ASH}_{8}\right.$ and $\left.\mathrm{C}_{4} \mathrm{AH}_{13}\right)$ could be identified. Unusually, no CSH bands were detected at this stage but a new previously unknown broad band was detected. This band was attributed to several intermediate compounds with metastable hexagonal aluminate phases (Martinez-Ramirez \& Frias, 2011). At $30 \mathrm{~h}$ the broad band attributed to the presence of $\mathrm{AlO}_{6}$ groups increased. Over a longer period of time (34 days), the portlandite bands as well as the broad band attributed to the metastable compounds containing hexagonal aluminate phases disappeared. In place of these bands, a new band appeared, attributed to a $\mathrm{C}_{3} \mathrm{ASH}_{6}$-type phase, probably formed from the metastable $\mathrm{AlO}_{6}$ phases (Martinez-Ramirez \& Frias, 2011). This band was found to increase over a longer period of time (up to 123 days curing).

The first paper on the evolution of hydraulic compounds in lime based materials using ${ }^{27} \mathrm{Al}$ and ${ }^{29} \mathrm{Si}$ NMR was published in 2013 by Frias and colleagues (Frias et al., 2013). In this paper, the same MK-lime system analysed in 2011 by Raman spectroscopy was studied with up to 123 days of curing. Within the first $30 \mathrm{~h}$, the 6-coordinated $\mathrm{Al}$ represented by the NMR peak at $9.6 \mathrm{ppm}$ started to 
appear due to the metastable phases $\mathrm{C}_{4} \mathrm{AH}_{13}$ and $\mathrm{C}_{2} \mathrm{ASH}_{8}$ and that this peak increased over time. In the meantime, the 5-coordinated Al peak reduced and the peak of the 4-coordinated Al shifted from 56 to $60 \mathrm{ppm}$. This shift was attributed to the formation of a stable cubic phase with tetrahedral $\mathrm{Al}\left(\mathrm{C}_{3} \mathrm{ASH}_{6}\right)$ or to the incorporation of $\mathrm{Al}$ in $\mathrm{CSH}$ gel (Frias et al., 2013). Interestingly, within the first $6 \mathrm{~h}$ there were no signs of CSH gel or stratlingite in the ${ }^{29} \mathrm{Si}$ or ${ }^{27} \mathrm{Al} \mathrm{NMR}$ signals but only the presence of 6-coordinated Al which was attributed to metastable phases and this suggested a new mechanism in the reaction kinetics (Frias et al., 2013).

Early signals from ${ }^{29} \mathrm{Si}$ were difficult to analyse because of a peak broadness at $-100 \mathrm{ppm}$, although it was noticed that the peak intensity decreased with the reaction time during the first hours and shifted toward less negative values ( $-93 \mathrm{ppm})$, indicating that the MK was becoming less polymerized (Frias et al., 2013). At $21 \mathrm{~h}$, a peak at $-86 \mathrm{ppm}$ assigned to $Q_{2}$ units was clearly visible and two signals at -76 and $-81 \mathrm{ppm}$ began to develop (Zendri et al., 2004). These three resonance peaks increased with hydration time until $30 \mathrm{~h}$. The peaks at -76 and $-81 \mathrm{ppm}$ were difficult to attribute but Frias and his group pointed out that peaks at $79.9 \mathrm{ppm}$ were attributed by other researchers to $Q_{0}$ units (part of amorphous or crystalline structures) and peaks at $-81 \mathrm{ppm}$ were attributed to $Q_{1}$ units of the CSH gel (Frias et al., 2013). In summary, Frias and his colleagues highlighted that at the early stage of the curing time (up to $30 \mathrm{~h}$ ) the metastable phases predominate over the most stable cubic phase and that the evolution they were able to reconstruct suggests that the three hydrated phases (metastable and cubic ones) were generated directly from the reaction between lime and MK rather than by a conversion reaction (Frias et al., 2013).

Other than for acquiring ${ }^{27} \mathrm{Al}$ and ${ }^{29} \mathrm{Si}$ spectra, NMR has also been used to study the moisture distribution in cement-based materials during drying, capillary water absorption and freeze-thaw cycling (Cano-Barrita et al., 2009). These results were obtained by measuring the $T_{2}$ relaxation time, a physical parameter related to the degree of confinement of the water molecules within the cement (Boguszynska et al., 2005). The NMR relaxation times are known to be sensitive to pore structure and reduction in pore size. A number of theories have been developed to explain why the relaxation time of water in porous materials is influenced by the pore size. It is generally agreed that collisions and/or interactions of water molecules with pore walls control the relaxation behaviour and, in particular, that the relaxation rate increases with the surface/volume ratio in pores (Beyea et al., 1998).

In 2009 Cano-Barrita and colleagues used the Carr-Purcell-Meiboom-Gill (CPMG) technique to monitor moisture changes in Portland cement mortar caused by hydration, drying and by pore size refinement. The technique is based on obtaining experimentally the Effective Transverse Relaxation Time ( $T_{2 \text { eff }}$ ) decay envelope (fig. 3 in Cano-Barrita et al., 2009) which is used to calculate the $T_{2 \text { eff }}$ relaxation time. This value can then be used to determine the signal amplitude $M_{(0)}$ in equation 1 which is proportional to the amount of water in fresh cement paste and in hardened mortar specimens (Cano-Barrita et al., 2009; Boguszynska et al., 2005; a more detailed description of the theory connected with this technique is available in Apih et al., 2001).

$$
M_{(t)}=M_{(0)} \exp \left(-\frac{t}{T_{2 \mathrm{eff}}}\right)
$$

As a result of their experiment Cano-Barrita and colleagues found a decrease in NMR signal due to the hydration of the cement that reduced with the amount of evaporable water in the sample (CanoBarrita et al., 2009). Although similar results were found by other groups (Boguszynska et al., 2005) this paper presents the first attempt to apply this technique to lime-based materials.

\section{NMR spectra of $M K$}

MK is produced from kaolinite, a hydrous layer silicate clay mineral. Its structural unit consists of a $\mathrm{Si}-\mathrm{O}$ tetrahedral sheet and an $\mathrm{Al}-\mathrm{O}(\mathrm{OH})$ octahedral sheet connected by $\mathrm{O}$ atoms (Liu et al., 2001). In this structure, silicon shares three oxygens with three silicate tetrahedra and an oxygen with two 6-coordinated Al atoms (Rocha \& Klinowski, 1990a).

When kaolinite is fired at temperatures between 550 and $950^{\circ} \mathrm{C}$ (Rocha and Klinowski found that the reactivity of $\mathrm{MK}$ is greatest at temperatures between 750 and $800^{\circ} \mathrm{C}$, while Edward found a temperature of $500^{\circ} \mathrm{C}$; a general overview on the studies of the dehydroxylation process of kaolinite has been described by Rocha \& Klinowski 1990a; 
Edwards, 2009; Rashad 2013), some of the $\mathrm{OH}^{-}$ anions within the $\mathrm{Al}$ octahedral layer are driven off the structure and some of the $\mathrm{Si}-\mathrm{O}$ bonds in the $\mathrm{Si}$ layer are broken so that order is lost in the direction perpendicular to the planes of layer stacking but some long range oreder is preserved within the planes (Liu et al., 2001).

This transformation is highlighted by ${ }^{29} \mathrm{Si}$ and ${ }^{27} \mathrm{Al}$ MAS NMR spectra. Liu and colleagues reported that the ${ }^{29} \mathrm{Si}$ magic angle spining nuclear magnetic resonance (MAS NMR) spectrum of kaolinite consists of a single resonance at $-91 \mathrm{ppm}$, which is characteristic of layer silicates and is assigned to silicon linked to three other silicon atoms and one aluminium atom via oxygens ( $Q_{3}$ sites; Liu et al., 2001). Rocha and Klinowski instead reported that highly ordered kaolinite gives two very close ${ }^{29} \mathrm{Si}$ peaks when the spectrum is recorded decoupling the ${ }^{1} \mathrm{H}$ (Rocha \& Klinowsky, 1990b). The chemical shift of ${ }^{29} \mathrm{Si}$ for metakaolinite is instead at $-106 \mathrm{ppm}$ which is characteristic of a distribution of sites where the silicon can also be linked to four other silicon atoms and suggests the presence of amorphous silica (Rocha \& Klinowski, 1990a; Liu et al., 2001). The ${ }^{27} \mathrm{Al}$ MAS NMR spectrum of kaolinite, in turn, contains a single peak at $-2 \mathrm{ppm}$ that is assigned to 6-coordinated Al. After calcination at $950^{\circ} \mathrm{C}$, metakaolinite exhibits two other resonances at $0-2 \mathrm{ppm}$ assigned to 6-coordinated $\mathrm{Al}$ and another at 56-59 $\mathrm{ppm}$ attributed to 4-coordinated Al. The broader and asymmetrical peak shapes of metakaolinite show its disordered structure (Rocha \& Klinowski, 1990a).

This paper describes the study of the hydration reaction between lime and MK during the first $42 \mathrm{~h}$ after mixing using ${ }^{1} \mathrm{H}$ and ${ }^{27} \mathrm{Al}$ NMR. A comparison is made with electrochemial impedence spectroscopy (EIS) data obtained at a similar temperature, $30^{\circ} \mathrm{C}$, and time duration. Results from both NMR and EIS were correlated and compared with data from chemical analysis. Thermal analyses (TGA/DSC) and scanning electron microscopy (SEM) are used to verify the formation sequence of previously reported hydraulic compounds while mercury intrusion porosimetry (MIP) and uni-axial compressive tests provided an insight into the changing physical and mechanical properties of pastes due to the formation of hydraulic phases.

\section{MATERIALS}

The hydraulic reactions between lime and MK were studied using a commercially available dry hydrated lime (commercial name Ultralime) classified as CL 90 according to the BS-EN 459-1 (European Committee for Standardization, 2010) and produced by Singleton Birch Ltd.

The MK used in the experiments was manufactured by Imerys Minerals Ltd. Its oxide composition, determined by X-ray fluorescence spectroscopy (XRF), is shown in Table 1. An energy dispersive $\mathrm{X}$-ray analysis identified the elements $\mathrm{Si}, \mathrm{Al}, \mathrm{O}, \mathrm{K}$ and $\mathrm{Fe}$ in order of decreasing peak intensity (Edwards, 2009).

Figure 1 shows the ${ }^{27} \mathrm{Al}$ NMR spectrum of MK (continuous line) with three broad resonances peaks at 3.6, 27.4 and $56.8 \mathrm{ppm}$ attributed, respectively, to octahedral (usually in the range 20 to $-10 \mathrm{ppm}$; Rocha, 1990; Andersen et al., 2003), pentahedral and 4-coordinated Al (Rocha \& Klinowski 1990a; Frias et al., 2013; Andersen et al., 2003).

For comparison, the continuous line in Fig. 2 depicts the ${ }^{29} \mathrm{Si}$ NMR spectrum of MK which displays a broad band characteristic of disordered $\mathrm{Si}$ environments (tetrahedral coordination) at about $100 \mathrm{ppm}$. This peak is characteristic of the dehydroxylated kaolin (Frias et al., 2013).

\section{METHODS}

According to previous research (e.g. Edwards, 2009; Aggelakopoulou et al., 2011), optimum mechanical properties are obtained from a 10:1 mixture of lime to $\mathrm{MK} \mathrm{w} / \mathrm{w}$ ratio; therefore a similar mix ratio has been adopted in this study. Initial tests were carried out over 28 days at 20 and $25 \pm 1^{\circ} \mathrm{C}$ in order to evaluate changes in EIS

TABLE 1. Oxide composition of the MK used in the tests (results in mass \%; data from: Moropoulou et al., 2004).

\begin{tabular}{lccccccccc}
\hline Oxide & $\mathrm{SiO}_{2}$ & $\mathrm{Al}_{2} \mathrm{O}_{3}$ & $\mathrm{Fe}_{2} \mathrm{O}_{3}$ & $\mathrm{CaO}$ & $\mathrm{MgO}$ & $\mathrm{K}_{2} \mathrm{O}$ & $\mathrm{Na}_{2} \mathrm{O}$ & $\mathrm{SO}_{3}$ & LOI \\
\hline Mass \% & 51.70 & 40.60 & 0.64 & 0.71 & 0.69 & 2.00 & 0.31 & 0.11 & 1.19 \\
\hline
\end{tabular}




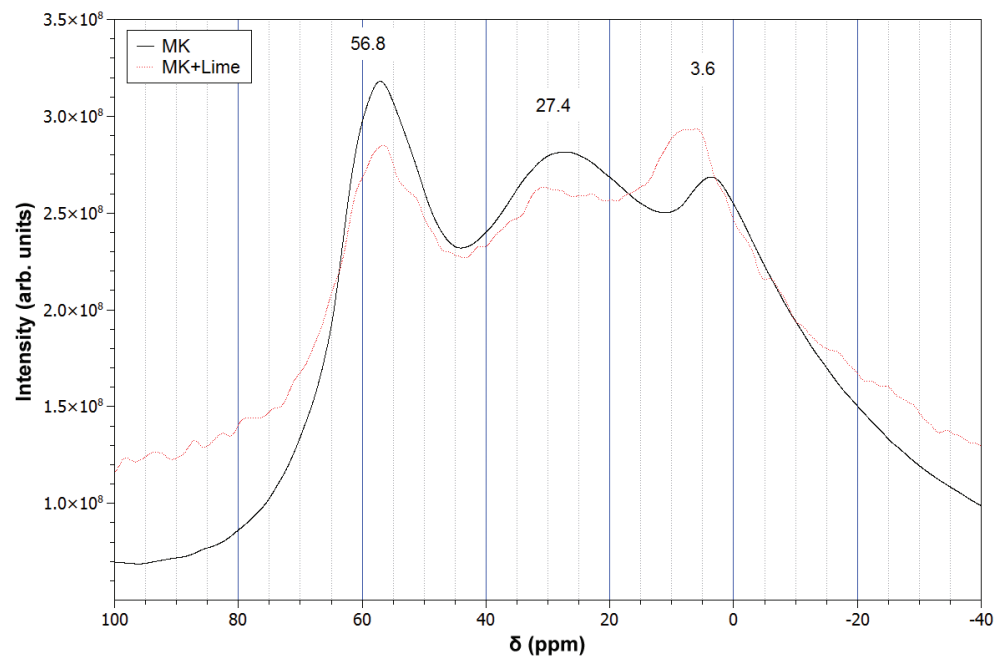

FIG. $1 .{ }^{27} \mathrm{Al}$ NMR spectra of MK before (continuous line) and after mixing with lime (dashed line).

response. To investigate the very beginning of the reactions tests over shorter periods of time (up to $42 \mathrm{~h}$ ) and at $30 \pm 1^{\circ} \mathrm{C}$ temperatures were subsequently carried out. In both cases, EIS was used to continuously monitor the impedance response of the pastes and identify changes in the signal that could be related to changes in the chemical, physical and/ or mechanical properties of the samples. Chemical physical and mechanical characterization of the pastes was carried out at the end of each week in the long term tests using TGA/DSC, SEM, MIP and uni-axial compressive strength. In order to study the chemical changes in the short term tests, NMR spectroscopy was used in association with the data already collected during the first week of the long term tests.

\section{Sample manufacture and electrochemical impedance spectroscopy (EIS)}

Pastes for the EIS tests were cast in an open top polycarbonate reaction cell of internal dimensions

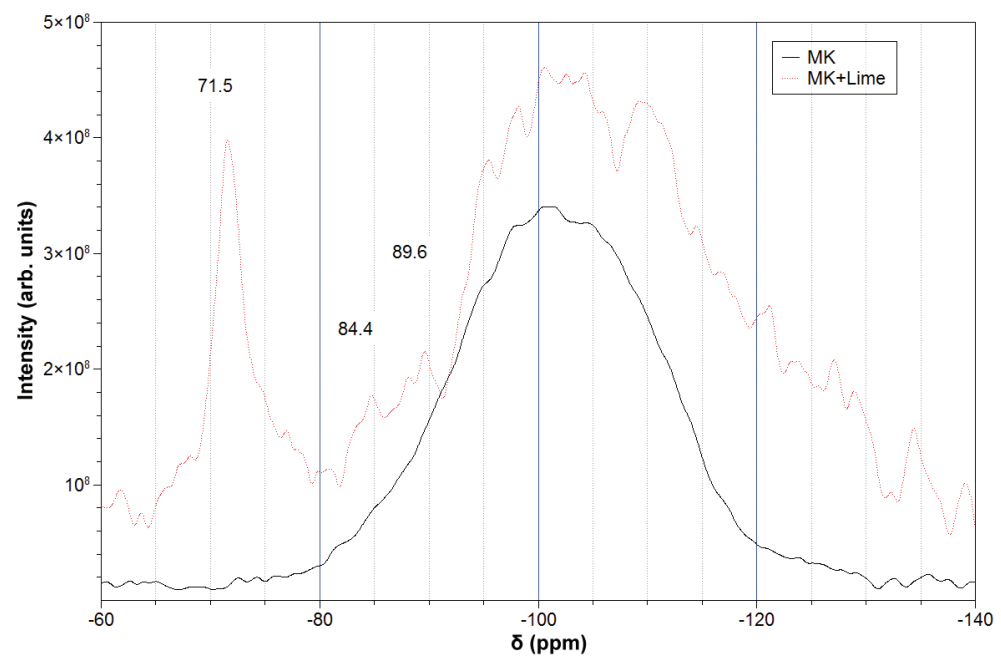

FIG. $2 .{ }^{29} \mathrm{Si}$ NMR spectra of MK before (continuous line) and after mixing with lime (dashed line). 
$50 \mathrm{~mm} \times 50 \mathrm{~mm} \times 50 \mathrm{~mm}$ containing two $50 \mathrm{~mm} \times 50 \mathrm{~mm} \times 3 \mathrm{~mm}$ stainless steel electrodes on opposing faces. A number of additional samples were cased into stainless steel molds for the chemical, physical and mechanical tests. Due to the small quantities of material, the required mixing was performed by hand in a plastic container. A mixing time of approximately eight minutes was considered adequate to obtain a homogeneous mixture using a water-lime ratio of 1.2:1.

Water evaporation and carbonation within the cell and the molds were minimized by covering the top surfaces that were open to air with a thin layer of plastic. In order to reduce the above mentioned processes during curing, the molds were inserted into a polystyrene box where the temperature was controlled by a thermostatic bath. Inside the box a beaker of water maintained humidity at near $100 \%$ while a petri dish containing lime putty was used to adsorb excess $\mathrm{CO}_{2}$. Before sealing the box, the plexiglass cell was connected to the impedance analyser and the EIS test was initiated. Long-term tests were carried out at 20 and $25 \pm 1^{\circ} \mathrm{C}$, while short term tests were carried out at $30 \pm 1^{\circ} \mathrm{C}$ over a period of $50 \mathrm{~h}$. In all cases the first measurement was recorded one hour after the initial mix.

EIS measurements were performed using a Solartron SI 1260 impedance/gain-phase analyser. Measurement acquisition was controlled with SMaRT (Solartron Materials Research and Test; Solartron Mobrey Ltd) software version 2.7.0. Impedance sweeps were taken in the frequency range $1 \mathrm{MHz}$ to $10 \mathrm{~Hz}$. The sample impedance, $Z_{(f)}$ at a frequency, $f$, is described in Ball et al. (2011) along with calculations of the relative permittivity $(\sigma)$ and AC conductivity $(\varepsilon)$ of the sample at a given frequency. In order to evaluate the response of EIS to the hydraulic reactions, a similar test with only air lime was performed simultaneously with the test on the hydration to evaluate behaviour of air lime itself.

\section{Uni-axial compressive strength}

Compressive strengths of the samples were determined using a Instron 'Fastrack' 8800 digitally controlled servo hydraulic system with $100 \mathrm{kN}$ load cell at a loading speed of $0.2 \mathrm{~mm} / \mathrm{min}$. Tests were performed at the end of each week of the long-term test using cubic samples of $40 \mathrm{~mm} \times 40 \mathrm{~mm} \times$ $40 \mathrm{~mm}$.

\section{Scanning electron microscopy (SEM)}

Microstructural information relating to phases within the hardened samples was obtained from fresh surface fractures using a JEOL JSM6480LV scanning electron microscope. Samples were attached to the holder with a carbon tape and then covered with a $30 \mathrm{~nm}$ thin layer of gold using an Edward Sputter S150B Coater. Images were taken using the secondary electron detector with an acceleration voltage of $15 \mathrm{kV}$, in high vacuum. Analysis were carried out on samples collected at the end of each compression test.

\section{Thermal analyses}

Thermal analyses were performed using a SETARAM thermo gravimetric/differential scanning calorimetry (TG/DSC) thermal balance model TGA $92-1750$ with a $1600^{\circ} \mathrm{C}$ module. Analyses were carried out on samples of weight between 13.5-14.5 $\mathrm{mg}$ using a dynamic regime, with a temperature rate of $10^{\circ} \mathrm{C} / \mathrm{min}$ up to $950^{\circ} \mathrm{C}$, starting from $20^{\circ} \mathrm{C}$. During the test, nitrogen gas was fluxed inside the furnace in order to prevent any reaction between the samples and atmospheric oxygen or $\mathrm{CO}_{2}$. Samples for the thermal analyses were collected after crushing of the cubic samples in the compression tests. In order to have a sample with an average content of moisture, fragments from the inner and the outer regions of the cubic samples were crushed with a pestle and mortar prior to particles greater than $250 \mu \mathrm{m}$ being removed with a sieve.

\section{Mercury intrusion porosimetry (MIP)}

Mercury intrusion porosimetry was performed using a Micrometrics AutoPore III, utilizing ports for both low and high pressure. A WIN9400 series version 2.00 software developed by the Micrometrics Instruments Corporation allowed analysis of data downloaded from the Micrometrics Interface Controllers. Penetrometers (pen and stem) for solid samples with $5 \mathrm{~mL}$ volume from Micrometrics where used. MIP analyses were carried out on samples collected after crushing of the cubic specimens in the compression tests.

\section{Nuclear magnetic resonance (NMR)}

Due to the small amount of material needed for this analysis ( $5 \mathrm{~g}$ of lime and $0.5 \mathrm{~g}$ of $\mathrm{MK}$ ), the 
required mixing was carried out by hand in a $50 \mathrm{~mL}$ glass beaker. A mixing time of approximately three minutes was considered adequate to obtain a homogeneous dry mixture of powders ready to be mixed with water. Then, $5 \mathrm{~mL}$ of distilled water was gradually added to the powder and continuously mixed for approximately three minutes inside the beaker in order to produce a paste suitable for insertion into the rotor. Once a suitable quantity of paste was put inside, the rotor was sealed, thus preventing any carbonation.

${ }^{29} \mathrm{Si},{ }^{27} \mathrm{Al}$ and ${ }^{1} \mathrm{H}$ 1D MAS NMR spectra were acquired on a Bruker Avance III 400 spectrometer operating at a $\mathrm{B}_{0}$ field of $9.4 \mathrm{~T}$ with ${ }^{29} \mathrm{Si},{ }^{27} \mathrm{Al}$ and ${ }^{1} \mathrm{H}$ Larmor frequencies of 79.5, 104.3 and 400.1 MHz, respectively. All spectra were acquired starting from 30 minutes after the mixture, at $30^{\circ} \mathrm{C}$ (rotor temperature) and compressed air was used as the driving gas for spinning the rotors. ${ }^{29} \mathrm{Si}$ MAS NMR spectra were recorded using a $7 \mathrm{~mm}$ probe employing a rotation speed of $5 \mathrm{kHz}$, using a $4.5 \mu \mathrm{s}$ radio-frequency (RF) excitation pulse length with a RF field strength of $56 \mathrm{kHz}$ ( $\pi / 2$ flip angle) and 60 $\mathrm{s}$ recycle delay. ${ }^{27} \mathrm{Al}$ MAS NMR spectra were recorded using a $4 \mathrm{~mm}$ probe with a spinning rate of $12 \mathrm{kHz}, 1 \mathrm{~s}$ recycle delay, $0.78 \mu \mathrm{s}$ RF excitation pulse (equivalent to a $\pi / 12$ flip angle). The flip angle pulse for ${ }^{27} \mathrm{Al}$ was optimized using an aqueous solution of $\mathrm{Al}\left(\mathrm{NO}_{3}\right)_{3}$.

The $T_{2}$ relaxation time of protons was recorded using the Carr-Purcell-Meiboom-Gill (CPMG) tech- nique according to the method described in CanoBarrita et al. (2009). For this analysis, a $4 \mathrm{~mm}$ probe with static rotor was used. The acquisition parameters were the following: $5 \mathrm{~s}$ recycle delay, $3.25 \mu \mathrm{s}$ and $6.5 \mu \mathrm{s}$ RF pulse length, using a RF field strength of $77 \mathrm{kHz}$, for the $\pi / 2$ and $\pi$ flip angles, respectively. The acquisition time for each experiment was 30 minutes. Chemical shifts are quoted in ppm from TMS for ${ }^{1} \mathrm{H}$ and ${ }^{29} \mathrm{Si}$ (using Q8M8 as standard $109.68 \mathrm{ppm}$, for the farthest downfield frequency peak). Aqueous solution of $\mathrm{Al}\left(\mathrm{NO}_{3}\right)_{3}$ was used as standard for ${ }^{27} \mathrm{Al}$.

\section{RESULTS AND DISCUSSION}

The results have been divided into two sections. The first addresses long term studies over 28 days, whereas the second describes a more detailed study using NMR over the initial hours of hydration.

\section{LONG TERM TEST AT 20 AND $25^{\circ} \mathrm{C}$ Electrochemical impedance spectroscopy}

Figure 3 shows changes in conductivity and relative permittivity, with frequency, from the 6th to the 28th day during the test at $20^{\circ} \mathrm{C}$ (similar results were obtained during the test at $25^{\circ} \mathrm{C}$ ). The plot shows a decrease in dielectric constant (that describes the electric polarizability) with frequency and a relatively small increase in AC conductivity

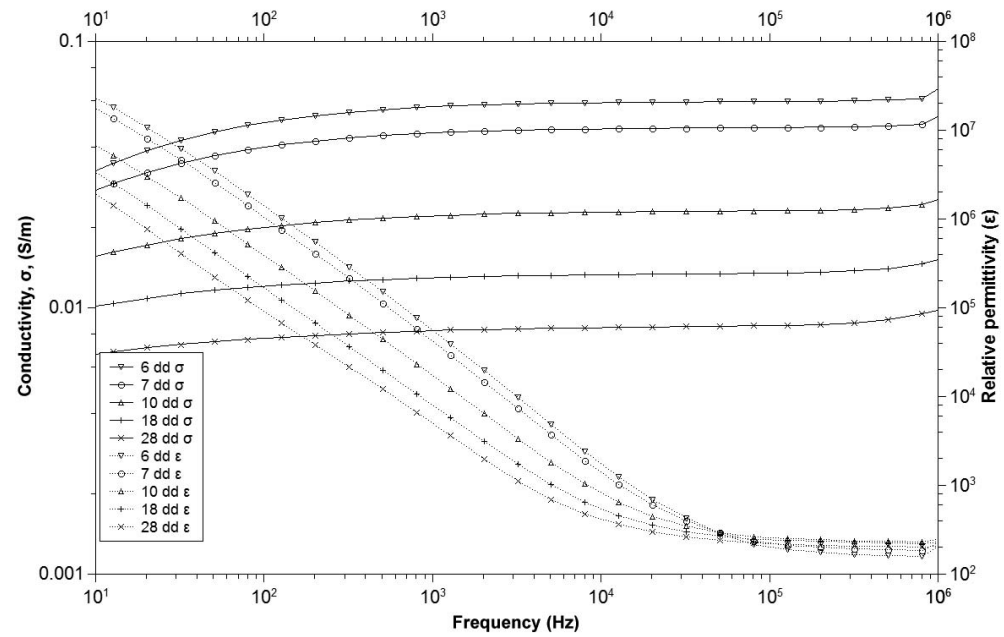

FIG. 3. Conductivity and relative permittivity as function of frequency at $6,7,10,18$ and 28 days, for the test at $20^{\circ} \mathrm{C}$. 


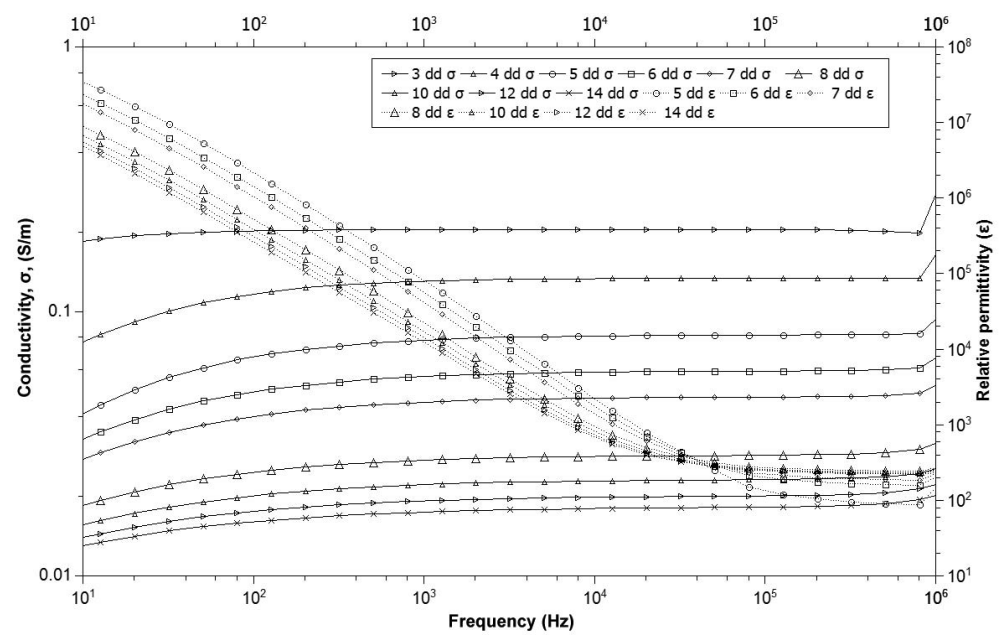

FIG. 4. Conductivity and relative permittivity as function of frequency from the 3 rd to the 14 th days, for the test at $20^{\circ} \mathrm{C}$.

with frequency. The sum of all polarization processes operating within the lime-MK structure contribute to this value at a given frequency of applied field. These processes, which may be superimposed, each have a characteristic relaxation frequency defining the polarization behaviour.

The permittivity exists across the entire frequency range under study and is indicative of a spread of relaxation frequencies. At the lower frequencies the dielectric constant rises to anomalously high values of around $10^{8}$. This behaviour is attributed to the dominating influence of electrode polarization below this frequency. Previous work suggests polarization is a combination of electric double-layer polarization and an interfacial polarization processes (Ball et al., 2011). The presence of conductive species, such as water can also lead to very high relative permittivity (Almond \& Bowen, 2004). With hardening time, a decrease is recorded both in conductivity and in relative permittivity.

A more detailed study of changes in dielectric constant and conductivity over the first two weeks shows a clear difference between 0 to 7 days and 7 to 14 days. Figure 4 shows that the decrease in conductivity and permittivity is more pronounced during the first 8 days compared to the following days.

Figure 5 shows changes in the real impedance $\left(Z^{\prime}\right)$ as a function of time for the tests at 20 and $25^{\circ} \mathrm{C}$. During the test at $20^{\circ} \mathrm{C}$, the impedance was measured at a frequency of $3.2 \mathrm{kHz}$, while during the test at $25^{\circ} \mathrm{C}$ the impedance was measured at $12.7 \mathrm{kHz}$. These frequencies corresponded to the minimum real impedance when plotted as a Nyquist plot, which is equivalent to the bulk resistance. A dramatic increase in resistance is shown after approximately $80 \mathrm{~h}$ from the initial mix. Impedance data of the following weeks indicates a further continuous increase in resistance following a levelling of the real part of the impedance. Results of the test carried out on a paste of air lime without MK prove that changes in the impedance are due to the hydraulic reactions (Fig. 5a)

\section{Compressive testing}

Results from the compression tests performed on the samples cured at $20^{\circ} \mathrm{C}$ are shown in Table 2.

TABLE 2. Maximum load (MPa) applied to the samples cured at $20^{\circ} \mathrm{C}$ before breaking.

\begin{tabular}{lcccc}
\hline & $1^{\text {st }}$ week & $2^{\text {nd }}$ week & $3^{\text {rd }}$ week & $4^{\text {th }}$ week \\
\hline Maximum load & 0.30 & 0.40 & 0.44 & 0.55 \\
\hline
\end{tabular}



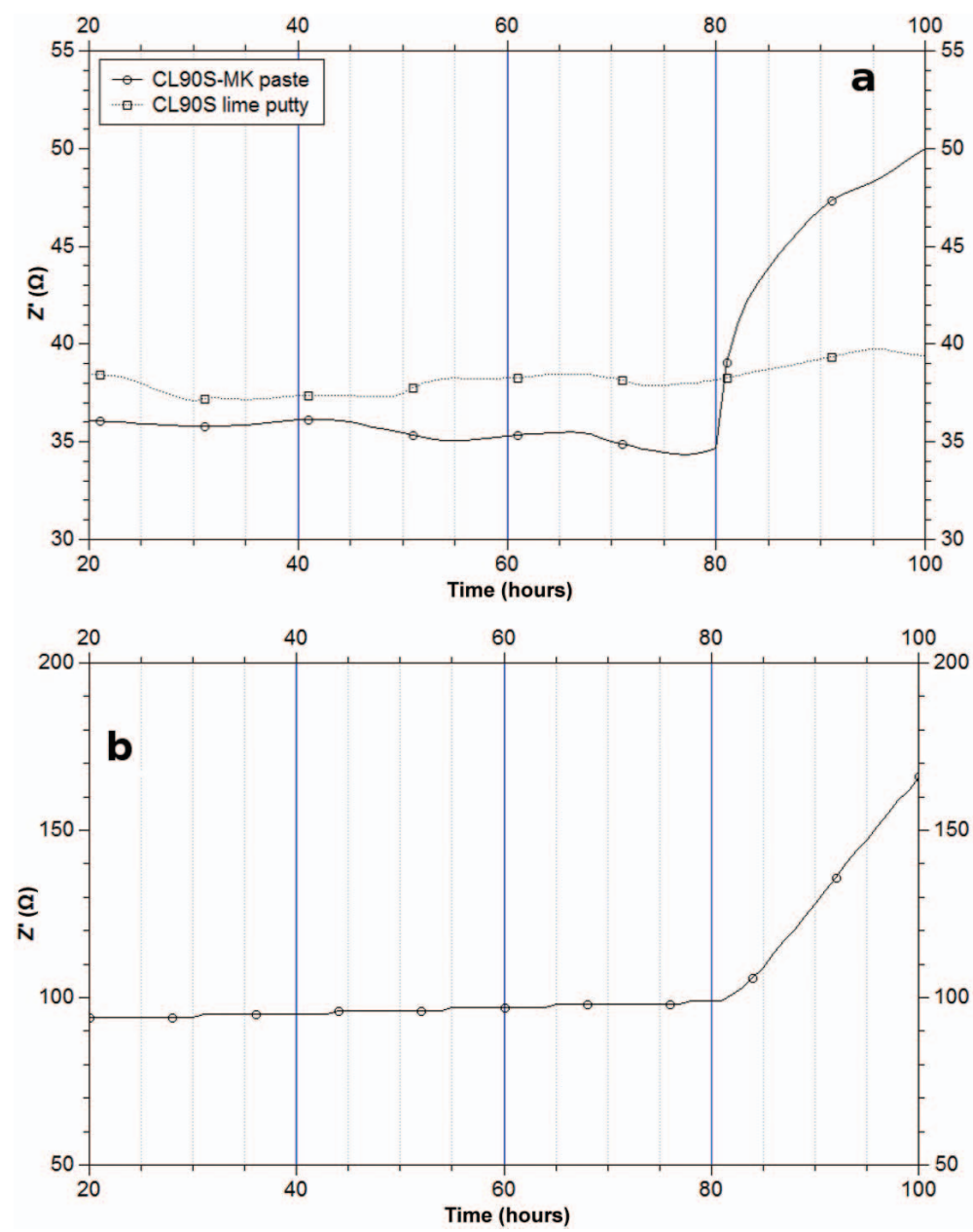

FIG. 5. Bulk resistance as function of time for the test at $20^{\circ} \mathrm{C}$ (b) and $25^{\circ} \mathrm{C}$ (a).

The one week old sample clearly demonstrates a maximum resistance of about $0.30 \mathrm{MPa}$. After two weeks the maximum load reaches $0.40 \mathrm{MPa}$ and at the end of the third week the maximum load rises again to $0.44 \mathrm{MPa}$. At the end of fourth week the maximum load rises to $0.55 \mathrm{MPa}$. In all samples the maximum value is followed by a gradual reduction of resistance without breaking of the sample. Similar results were found during the test at $25^{\circ} \mathrm{C}$ temperature.

\section{Miscrostructural analysis}

The microstructure of a clean fracture surface is characterized by the presence of MK plates randomly distributed throughout the porous matrix. Plates can be single or grouped in packs of 2-8 plates and it is often possible to recognize plate fragments intimately mixed and incorporated into the lime matrix. In the sample cured for one week it is possible to observe bridges of amorphous phases between two plates and the growth of amorphous structures on the edge of the plates. MK plates were readily identifiable in the one week old sample (Fig. 6). However it is noteworthy that due to the progress of the reaction of MK with lime the plates became covered and harder to identify in the two three and four week old pastes. SEM microstructure of the four week old sample shows a higher compactness compared with the microstructure of the one week old sample. 


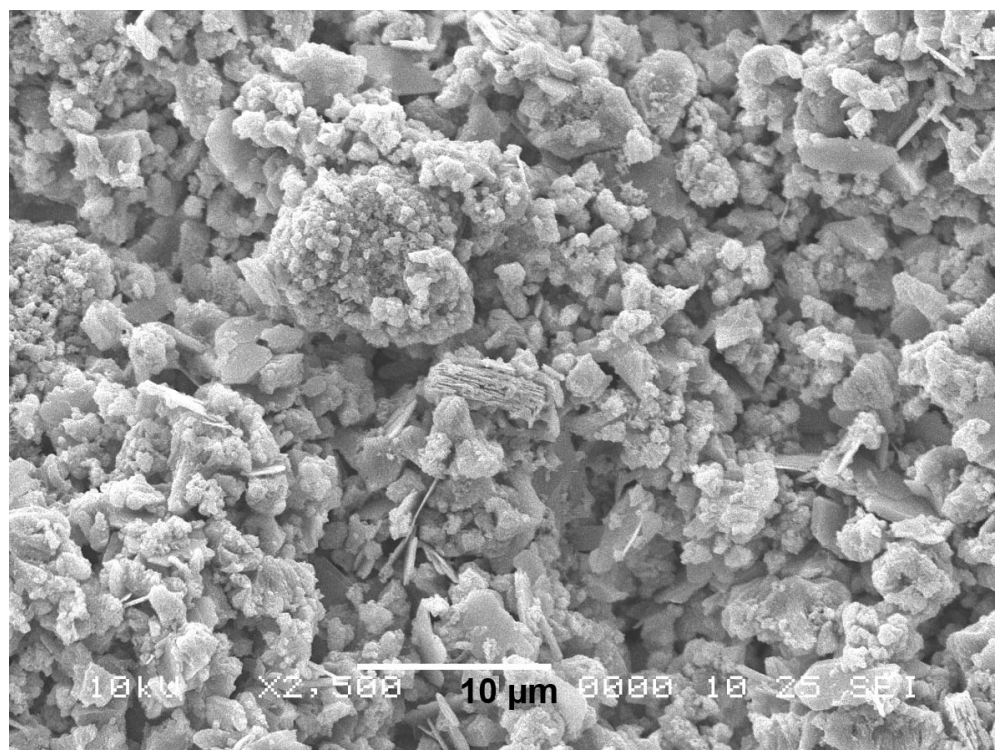

FIG. 6. SEM image of the lime-MK paste at one week cured at $20^{\circ} \mathrm{C}$ temperature.

\section{Thermal analysis}

Figure 7 shows the results of the TGA carried out on samples cured at $20^{\circ} \mathrm{C}$. The endothermic reaction and weight loss due to dehydration of $\mathrm{CSH}$ occurs in the temperature range $110-140^{\circ} \mathrm{C}$ (Rojas \& de Roja, 2003; Moropoulou, et al., 2004; Bakolas, et al., 2006). Calculations using the TG data within this temperature range (Table 3) show an increase in the formation of CSH between the first and the second week and a similar decrease between the second and the third week (Fig. 8). The DSC curves show a peak between $140-200^{\circ} \mathrm{C}$ attributed to the dehydration of the hydraulic compound stratlingite $\left(\mathrm{C}_{2} \mathrm{ASH}_{8}\right.$; Cabrera \& Rojas, 2001). Calculations show a clear increase for this compound between the

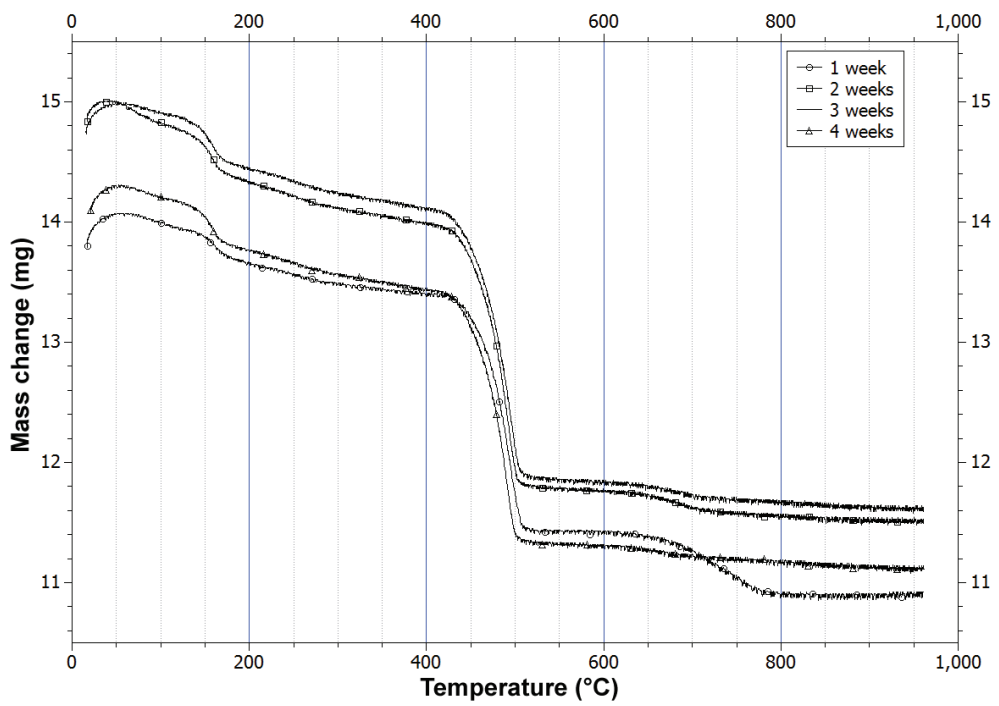

FIG. 7. Thermogravimetric analysis of lime-metakaolin pastes cured at $20^{\circ} \mathrm{C}$ up to 4 weeks. 
TABLE 3. Weight loss in percentage calculated for the different hydraulic compounds formed at $20^{\circ} \mathrm{C}$ temperature from the data of the thermo-gravimetric analysis.

\begin{tabular}{lccccc}
\hline Sample & $\mathrm{CSH}$ & $\mathrm{C}_{2} \mathrm{ASH}_{8}$ & $\mathrm{C}_{4} \mathrm{AH}_{13}$ & $\mathrm{C}_{3} \mathrm{ASH}_{6}$ & $\mathrm{Ca}(\mathrm{OH})_{2}$ \\
\hline 1 week & 0.58 & 1.88 & 0.80 & 0.80 & 14.49 \\
2 weeks & 0.67 & 2.43 & 1.01 & 1.08 & 15.03 \\
3 weeks & 0.54 & 2.38 & 1.09 & 1.02 & 15.34 \\
4 weeks & 0.57 & 2.55 & 0.92 & 1.13 & 15.04 \\
\hline
\end{tabular}

first and the second week and a less pronounced increase after the second week. A second less clear peak which is visible by close inspection of the one week old sample between $200-270^{\circ} \mathrm{C}$ is attributed to hydrogarnet $\mathrm{C}_{4} \mathrm{AH}_{13}$ (Bakolas et al., 2006, Moropoulou et al., 2004, Cabrera \& Rojas, 2001). Calculations for this compound show a clear increase between the first and the second week that continue in the third week. Decomposition of $\mathrm{C}_{3} \mathrm{ASH}_{6}$ occurs between 270 and $380^{\circ} \mathrm{C}$. Between the first and second week, a pronounced increase in the amount of this compound was detected while after the second week the increase was less pronounced. The large weight loss around $500^{\circ} \mathrm{C}$ is due to the dehydration of calcium hydroxide. Tests at $25^{\circ} \mathrm{C}$ confirm the results obtained at lower temperature and allows a better evaluation of the phase formation and evolution (Ball et al., 2012).
According to these results (Table 4, Fig. 9), CSH phases are clearly identified at the end of the first week and their abundance decrease at the end of the second remaining almost constant at the end of the third week. Stratlingite is the main phase present at the end of the first week which then increases over the following three weeks. Calcium aluminate hydrate $\mathrm{C}_{4} \mathrm{AH}_{13}$ has a similar behaviour as well as the $\mathrm{C}_{3} \mathrm{AH}_{6}$ while $\mathrm{Ca}(\mathrm{OH})_{2}$ remains almost constant over the three weeks.

\section{Mercury intrusion porosimetry (MIP)}

Mercury intrusion porosimetry of lime-MK paste aged up to four weeks is shown in Fig. 10. Results of the one week old sample shows that pores are mainly in the 400-1200 $\mathrm{nm}$ diameter range but a small quantity of smaller pores in the range

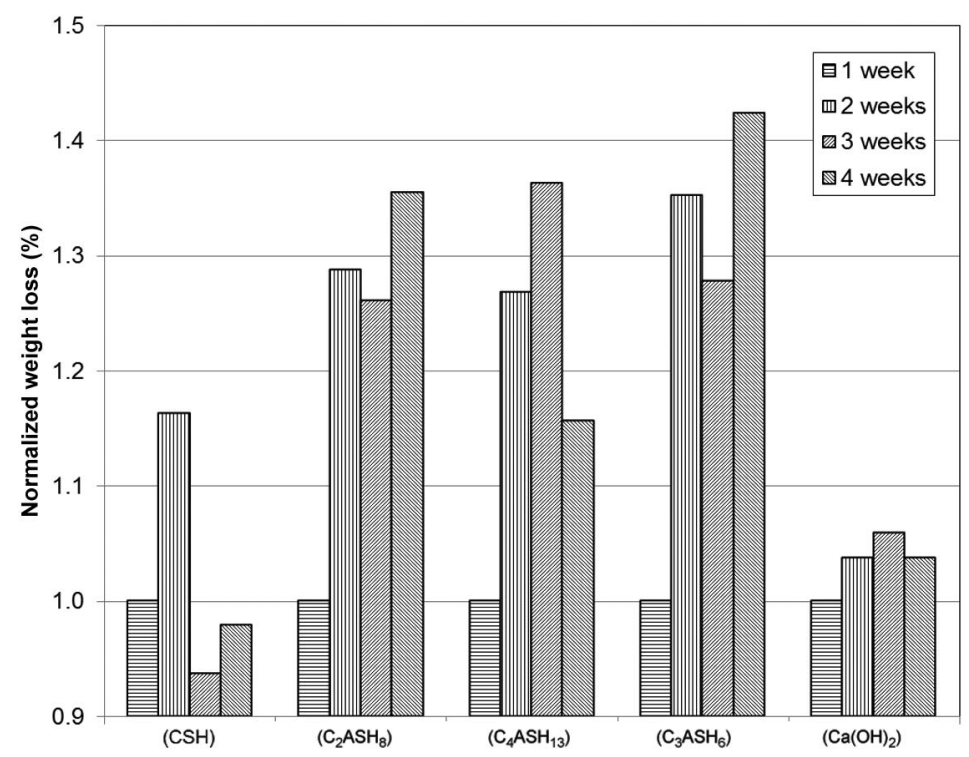

FIG. 8. Change in the amount of different hydraulic compounds formed at $20^{\circ} \mathrm{C}$ temperature. Calculation in percentage from the thermo-gravimetric analysis, normalized to the value of the first week. 
TABLE 4. Weight loss in percentage calculated from the termo-gravimetric analysis at different temperature ranges for the test at $25^{\circ} \mathrm{C}$ (from: Ball et al., 2012).

\begin{tabular}{lrcccc}
\hline Sample & $\mathrm{CSH}$ & $\mathrm{C}_{2} \mathrm{ASH}_{8}$ & $\mathrm{C}_{4} \mathrm{AH}_{13}$ & $\mathrm{C}_{3} \mathrm{ASH}_{6}$ & $\mathrm{Ca}(\mathrm{OH})_{2}$ \\
\hline 1 week & 11.13 & 1.34 & 0.89 & 0.34 & 6.98 \\
2 weeks & 6.25 & 1.77 & 0.94 & 1.12 & 6.84 \\
3 weeks & 6.68 & 2.14 & 1.09 & 1.15 & 7.12 \\
\hline
\end{tabular}

between 4 and $200 \mathrm{~nm}$ are also detected. Results on the two week old samples show a slight reduction in the pore range between 20 and $600 \mathrm{~nm}$ diameter while an increase is visible in the pores of $800 \mathrm{~nm}$ diameter. This small increase is shown also in the total intrusion volume of mercury and the reduction in volume of median pore diameter. In contrast to the week one and three, a significant pore reduction in the porosity is detected in the week four (Khatib \& Wild, 1996; Frias \& Cabrera, 2000).

\section{SHORT TERM TEST AT $30{ }^{\circ} \mathrm{C}$}

\section{Electrochemical impedance spectroscopy}

EIS tests at $30^{\circ} \mathrm{C}$ were carried out only $50 \mathrm{~h}$ after the initial mix to investigate the initial stages of the hydraulic reactions and, in particular, the increase in bulk resistance found at about $80 \mathrm{~h}$ in the tests at 20 and $25^{\circ} \mathrm{C}$ (respectively Fig. $5 \mathrm{~b}$ and a). Figure $11 \mathrm{~b}$ shows changes in the real part of the impedance during the test at $30^{\circ} \mathrm{C}$. As already noted for the tests at 20 and $25^{\circ} \mathrm{C}$, after an initial stability, the bulk resistance suddenly increases but, differently from the tests at lower temperature, this increase is clearly detected after about $35 \mathrm{~h}$ from the initial mixing.

By examining the changes in conductivity and dielectric constant within the first $42 \mathrm{~h}$ a decrease in conductivity until $26 \mathrm{~h}$ is visible from the beginning of the test and a sharper decrease after this time. An almost symmetrical behaviour is recognizable (Fig. 11a) in the dielectric constant that slowly rises during the first $26 \mathrm{~h}$ and, then exhibits a rapid increase.

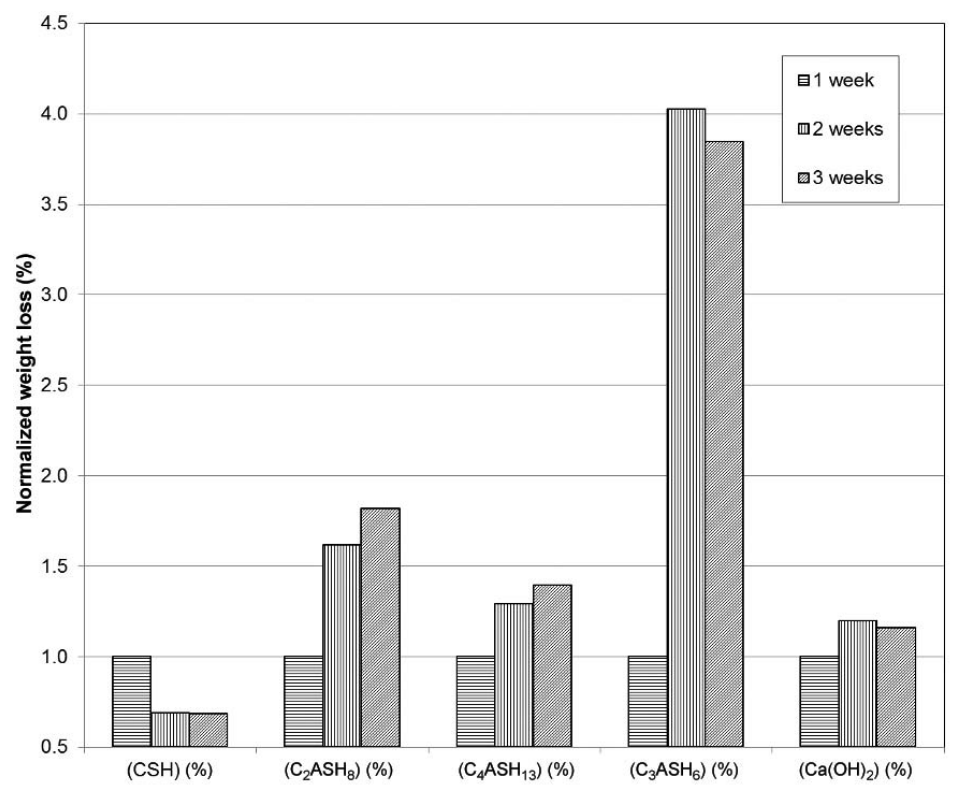

FIG. 9. Weight loss for different hydraulic compounds formed at $25^{\circ} \mathrm{C}$ temperature. Calculation in percentage from the thermo-gravimetric analysis, normalized to the value of the first week. 


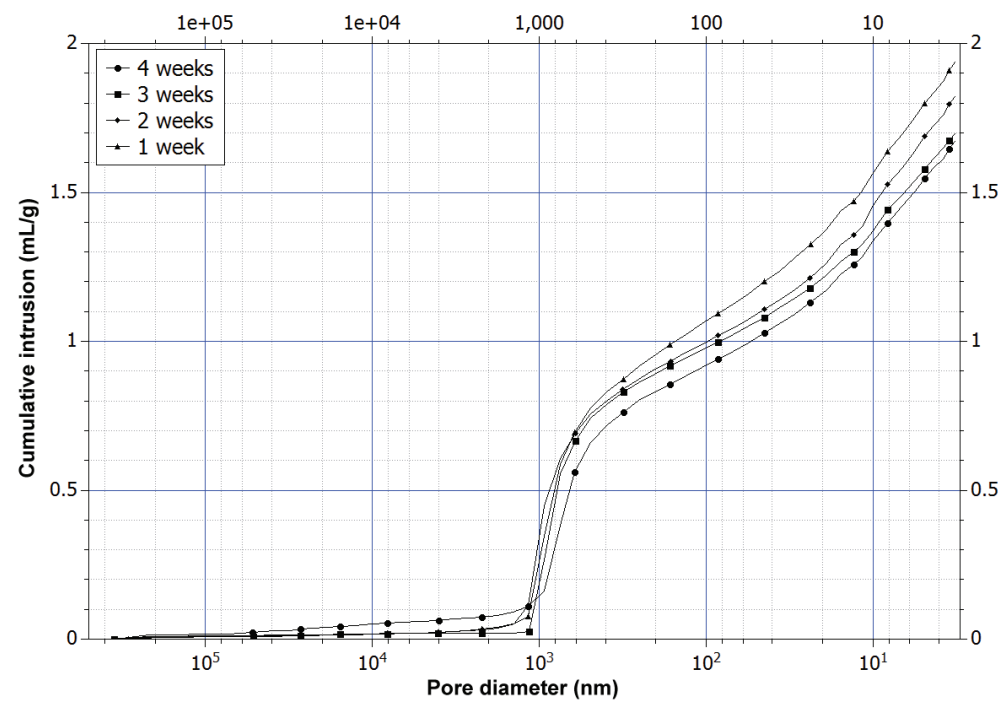

FIG. 10. Mercury intrusion porosimetry results of lime-MK pastes cured at $20^{\circ} \mathrm{C}$ and aged up to four weeks.

\section{NUCLEAR MAGNETIC RESONANCE}

NMR analysis was used to investigate changes in bulk resistance highlighted by EIS during the very early stages of hydration. Tests were carried out at $30^{\circ} \mathrm{C}$ to allow comparison with the EIS results.

\section{${ }^{27} \mathrm{Al}$ and ${ }^{29} \mathrm{Si}$ MAS NMR spectra}

The dashed line in Fig. 1 shows the ${ }^{27} \mathrm{Al}$ NMR spectrum of MK about 30 minutes after the initial mix. Comparison of this spectrum with the spectrum of non-reacted MK (in the same figure) highlights a reduction in the 4 and 5-coordinated $\mathrm{Al}$ peak and an increase in the peak of 6-coordinated Al suggesting a reaction between lime and MK at least 30 minutes after the initial mix.

Figure 12 shows changes in the coordination number of $\mathrm{Al}$ over a longer period of time (up to $42.5 \mathrm{~h}$ ). Measurements taken every $3.5 \mathrm{~h}$ show an initial increase in the peak of 6-coordinated $\mathrm{Al}$ and a later reduction, followed by another increase and reduction cycle. Peaks of 5- and 4-coordinated Al, instead, show a continuous decrease until disappearance of the 5-coordinated $\mathrm{Al}$ and an almost complete disappearance of the 4-coordinated Al. A plot of the normalized 6-coordinated Al using the the 4-coordinated peak as a reference is shown in Fig. 11b. This highlights the initial increase and the subsequent stabilization or decrease in the number of sites of octahedral Al.
The dashed line in Fig. 2 represents the ${ }^{29} \mathrm{Si}$ MAS NMR spectrum, $\sim 8 \mathrm{~h}$ after the MK was mixed with lime. In this spectrum a new sharp peak at $71.5 \mathrm{ppm}$ is recognizable as well as two smaller peaks at 84.8 and $89.6 \mathrm{ppm}$. Despite the fact that in some cases these peaks could be considered noise, for some authors, the first peak can also be attributed to $Q_{0}$ sites (isolated tetrahedra; Cong \& Kirkpatrick, 1996; Frias et al., 2013) while the last two peaks can be attributed to the $Q_{2}(84.8 \mathrm{ppm})$ or $Q_{3}(89.6 \mathrm{ppm})$ units formation. Chemical shifts in the range -85 to -90 in the ${ }^{29} \mathrm{Si}$ MAS NMR spectra correspond to $\mathrm{Si}$ with one nearest $\mathrm{Al}$ neighbour (Liu et al., 2001) while the peak at 84.8 corresponds to $\mathrm{CSH}$ gel that, according to other researchers, is the first hydrated phase formed in this type of mix (Cong \& Kirkpatrick, 1996; Frias et al., 2013).

\section{$T_{2}$ spectrum}

Figure $11 \mathrm{~b}$ also shows the relaxation time $T_{2}$ as a function of cure time. Contrary to obervations by other researchers, for cement based mixtures the $T_{2}$ time in MK-lime pastes shows an initial regular increase that reaches a maximum at about $35 \mathrm{~h}$. Comparison of these data with the increase in 6-coordinated $\mathrm{Al}$ and with the changes of the real part of the impedance over the time highlights a correspondence among the data that suggests that EIS is able to detect specific chemical changes 

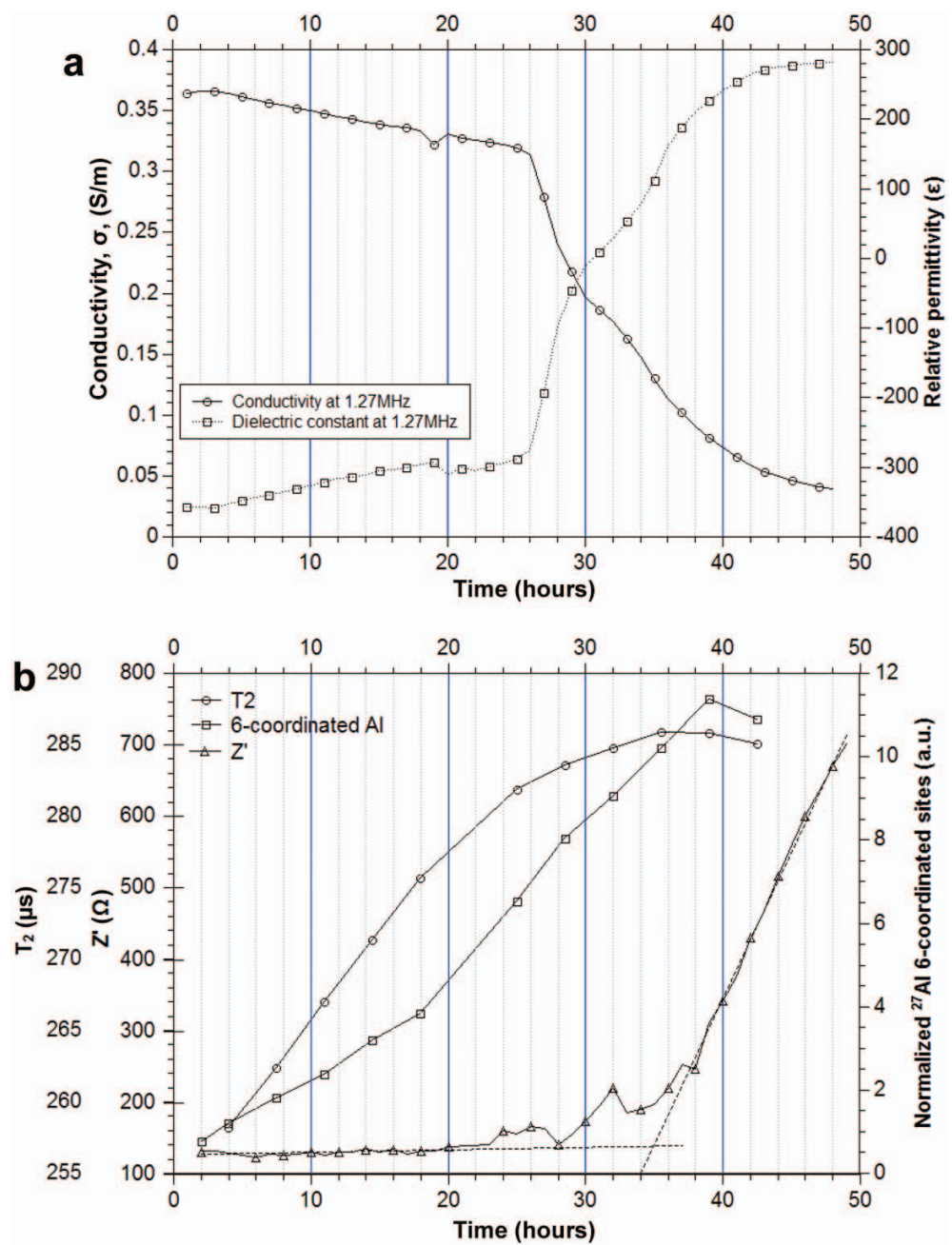

FIG. 11. (a) Changes in conductivity and dielectric constant during the first $48 \mathrm{~h}$ of the test at $30^{\circ} \mathrm{C}$ temperature. Measurement were taken at $1.27 \mathrm{MHz}$ frequency (b) Comparison of the $T_{2}$ relaxation time, ${ }^{27} \mathrm{Al}$ MAS NMR spectrum and $Z^{\prime}$ EIS spectrum.

witin the paste useful in monitoring the hardening process of lime-MK mixtures (Fig. 11b).

\section{DISCUSSION}

Despite the fact that spins $>1 / 2$ (quadrupolar nuclei) give asymmetric lines, even if the materials are very ordered (depending on the local symmetry of the electronic cloud around the nuclei; in practice a lot of local disorder may result in more symmetrical lines because of distribution of local environments), the broad and asymmetrical shape of the NMR signal of ${ }^{27} \mathrm{Al}$ produced by the $\mathrm{MK}$ used for the mixes (Fig. 1) can be considered as a suggestion of the existence of a disordered structure (Rocha \& Klinowski, 1990a; Frias et al., 2013). According to the results of other researchers the reactivity of MK is greater when the population of 6-coordinated $\mathrm{Al}$ is minimal and the 4- and 5-coordinated $\mathrm{Al}$ populations are at a maximum (Edwards 2009; Frias et al., 2013). In agreement with these data is also the ${ }^{29} \mathrm{Si}$ NMR spectrum of MK where a broad band representative of a range of environments including some with at least an $\mathrm{Al}$ atom in the second coodrination with $Q_{4}$ type $\mathrm{Si}$ bonds is visible (Fig. 2; Frias et al., 2013). All these data 


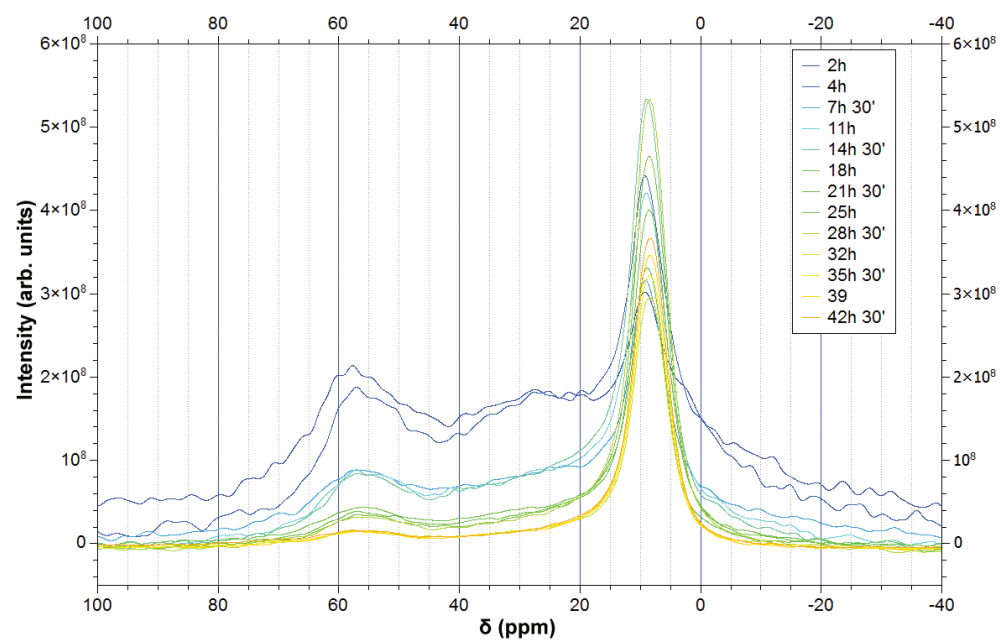

FIG. 12. ${ }^{27} \mathrm{Al}$ NMR spectra of MK mixed with lime over a period of time of $42 \mathrm{~h}$ and 30 minutes at $30^{\circ} \mathrm{C}$ temperature.

suggest that the MK used in the tests has lost its order along the axes perpendicular to the plates ( $a b$ plane) and, consequently, can be considered suitable for studying the hydraulic reactions with lime.

Results of thermo-gravimetric analysis suggest that all the samples contained a certain amount of water even after four weeks and that negligible carbonation had taken place. This observation is also supported by the absence of angular calcium carbonate crystals in the SEM micrograph. Consequently, the only reaction that can be considered as cause for the mechanical and physical characteristics acquired by the hardened samples at 20 and $25^{\circ} \mathrm{C}$ is the hydration process of silicon and aluminium. The same process can be considered also for the sample at $30^{\circ} \mathrm{C}$.

The results of thermal analysis highlight that at the end of the first week, all the hydraulic compounds already found by other researchers in similar mixes $\left(\mathrm{CSH}, \mathrm{C}_{2} \mathrm{ASH}_{8}, \mathrm{C}_{4} \mathrm{AH}_{13}\right.$ and $\mathrm{C}_{3} \mathrm{ASH}_{6}$ ) were formed. The only difference between the tests at 20 and $25^{\circ} \mathrm{C}$ is the amount of $\mathrm{CSH}$ produced at the end of the first week and the time needed to detect the reduction in the same compound. This difference can be due to the temperature (higher in the second test) that accelerated the formation of $\mathrm{CSH}$.

Among all the hydraulic compounds detected, $\mathrm{CSH}$ is the only one that reduces drastically after one/two weeks. $\mathrm{C}_{2} \mathrm{ASH}_{8}, \mathrm{C}_{4} \mathrm{AH}_{13}$ and $\mathrm{C}_{3} \mathrm{ASH}_{6}$ grow substantially between the beginning and the end of the tests (although in the test at $20^{\circ} \mathrm{C}$
$\mathrm{C}_{4} \mathrm{AH}_{13}$ showed a decrease between the third and the fourth week). Because $\mathrm{C}_{3} \mathrm{ASH}_{6}$ is detected after the end of the first week, it is difficult to evaluate if its formation is from metastable phases (Cabrera \& Rojas, 2001; Moropoulou et al., 2004) or by direct reaction between lime and MK (Cabrera \& Rojas, 2001) but in the test at $25^{\circ} \mathrm{C}$ the increase in $\mathrm{C}_{3} \mathrm{ASH}_{6}$ corresponds to the decrease in $\mathrm{CSH}$ and this suggests that the transformation mechanism may have taken place.

The near constant amount of $\mathrm{Ca}(\mathrm{OH})_{2}$ detected over the four week monitoring period suggests that all the calcium needed for the reactions with the MK reacted during the first week. This is in agreement with the results of other researchers that found lime is consumed rapidly in the initial period of reaction (up to $50 \mathrm{~h}$ in a 1:1 lime:MK ratio, 2.37 water:solid ratio; Cabrera \& Rojas, 2001).

Results of the MIP suggest that formation of metastable and stable hydraulic phases between the first and the second week (test at $20^{\circ} \mathrm{C}$ ) caused changes in the pore size distribution between 20 and $800 \mathrm{~nm}$ diameter. Changes between the first two weeks are also evident in the slope of the strain-stress curve. Increases in the maximum load, instead, do not seems to be influenced by $\mathrm{CSH}$ formation.

Formation of solid phases between the first and the second week is reflected by the conductivity and the relative permittivity that show a pronounced reduction in the measurements during the second week. A reduction in freely rotational water 
molecules associated with the formation of the hydraulic phases is consistent with the results.

Considering the results of MAS NMR, it is possible to highlight that during the first $8 \mathrm{~h}$ of reaction, $\mathrm{CSH}$ (resonance at $-84.8 \mathrm{ppm}$ ) and a compound containing $\mathrm{Si}$ and $\mathrm{Al}$ (resonance peak at $-89.3 \mathrm{ppm}$, which is likely to be $\mathrm{C}_{2} \mathrm{ASH}_{8}$ ) is formed (Frias et al., 2013). According to the results of Cong \& Kirkpatric (1996) and to the phase diagram developed by Damidot and Glasser for the $\mathrm{CaO}-\mathrm{Al}_{2} \mathrm{O}_{3}-\mathrm{SiO}_{2}-\mathrm{H}_{2} \mathrm{O}$ system (Damidot \& Glasser, 1995), the CSH formed in these experiments is likely to be $\mathrm{CSH}(\mathrm{I})$ with a tobermorite-like structure.

Within the same first $8 \mathrm{~h}$, another part of the $\mathrm{Si}$ contained in the original MK dissolved to form $Q_{0}$ tetrahedra (peak at $-71.5 \mathrm{ppm}$ ) and the rest of the MK remained within a short distance order as documented by the broad resonance peak around $100 \mathrm{ppm}$ and by the MK plates still visible at the end of the first week in the SEM image (Fig. 6).

Looking in detail at the initial stages of the reaction, it is possible to highlight that results of the ${ }^{27} \mathrm{Al}$ MAS NMR analysis show an increase in the 6coordinated $\mathrm{Al}$ peak during the first $42 \mathrm{~h}$ that can be interpreted as formation of the metastable phase $\mathrm{C}_{4} \mathrm{AH}_{13}$ and, as already said, of $\mathrm{C}_{3} \mathrm{ASH}_{6}$. Formation of $\mathrm{C}_{4} \mathrm{AH}_{13}$ can be promoted by the presence of a supersaturated aqueous solution of $\mathrm{Ca}(\mathrm{OH})_{2}$ in particular during the early stages of hydration. High concentrations of $\mathrm{Ca}^{2+}$ and $\mathrm{OH}^{-}$in the pore solution maintain a pore fluid composition that allows precipitation of $\mathrm{C}_{4} \mathrm{AH}_{13}$ (Cabrera \& Rojas, 2001).

The normalized plot of the 6-coordinated Al sites (lower part of Fig. 11) demonstrates that formation of hydraulic compounds with the capture of ions from the solution to the solid phases starts at the very beginning of the test. Furthermore, at $\sim 18 \mathrm{~h}$ the formation of 6-coordinated $\mathrm{Al}$ sites starts to increase reaching a maximum (or a relative maximum) at $\sim 39 \mathrm{~h}$.

Interestingly, at the same time the $T_{2}$ relaxation time (Fig. 11b) increases due to the dissolution of $\mathrm{Ca}(\mathrm{OH})_{2}$ promoted by the capture of $\mathrm{Ca}^{2+}$ ions in the newly formed solid phases. The increase in the relaxation time is regular until around $36 \mathrm{~h}$, when it starts to decrease or stabilize. At this time all the $\mathrm{Ca}^{2+}$ needed for the formation of hydraulic compounds seems to be acquired and it is likely that from this time on no more ions are introduced in the solution. Consequently, starting from $18 \mathrm{~h}$ from the initial mix, the collisions and/or interactions of water molecules with pore walls control the relaxation time according to the results already found by other researchers for the cement-based materials (Beyea et al., 1998). It is possible that until about $18 \mathrm{~h} T_{2}$ is determined by other processes and, then, when the pores reach a certain size the interaction with inner surfaces determines $T_{2}$ and the gradient of the curve (derivative) decreases.

The end of the increase of 6-coordinated $\mathrm{Al}$ sites being coincidental with the beginning of decrease of the relaxation time suggests that the decrease in the relaxation time can only be partially due to the formation of hydrated compounds containing aluminium. Formation of $\mathrm{CSH}$ can be the other reason for the $T_{2}$ reduction.

The results of the EIS bulk resistance measurements (Fig. 11b) show that the end of the initial stability coincide with the increase in the 6coordinated $\mathrm{Al}$ sites and with the decrease in the $T_{2}$ relaxation time. The plot of conductivity and relative permittivity highlights this time by a relative minimum (conductivity) and maximum (dielectric constant; Fig. 11a). The maximum in the $T_{2}$ curve, instead, coincides with the theoretical change in gradient of the bulk resistance curve. Overall, the results suggest that the bulk measurement obtained with the EIS method is able to detect the end of the dissolution of $\mathrm{Ca}(\mathrm{OH})_{2}$ by measuring the effect of the reduction in the amount of $\mathrm{OH}^{-}$ ions introduced in the solution by the dissolution process.

\section{CONCLUSIONS}

The results presented demonstrate formation and reaction kinetics of hydraulic compounds produced by interaction of lime with metakaolin and show their influence on physical, chemical and mechanical characteristics of pastes. Results, in particular, show formation of hydraulic compounds such as $\mathrm{CSH}, \mathrm{C}_{4} \mathrm{AH}_{13}$ and $\mathrm{C}_{3} \mathrm{ASH}_{6}$ and their evolution over the time. MIP analysis demonstrates changes in pore size distribution related to the formation and trasformation of hydraulic compounds whereas uniaxial compressive strenght tests show the related changes in mechanical characteristics.

The results also demonstrate the potential of EIS as a nondestructive technique for real time in situ monitoring and study of the the reaction between lime and MK. Changes of impedance response with time are shown to be associated with reaction 
kinetics. Changes in bulk measurements at the very beginning of the tests can be associated with the end of $\mathrm{Ca}(\mathrm{OH})_{2}$ dissolution. Changes in conductivity and relative permittivity over a longer period of time (1-2 weeks) are able to detect the formation of hydraulic compounds that are likely to be the cause of porosity reduction. The study demonstrates the importance of NMR spectroscopy for the study of hydraulic reactions in lime-based materials. NMR provides a detailed continuous insight into the chemical reactions of aluminium and silicon that cannot be achieved through other methods.

\section{ACKNOWLEDGMENTS}

The authors would like to thank Singleton Birch Ltd and Imerys Minerals Ltd. for providing the materials used in the tests. Thanks are also due to the Engineering and Physical Sciences Research Council (EPSRC), for projects EP/I001204/1 and EP/J004219/1 and the UK India Education and Research Initiative (UKIERI II) coordinated by the British Council, New Delhi, India, for financial support through a thematic partnership.

\section{REFERENCES}

Aggelakopoulou E., Bakolas A. \& Moropoulou A. (2011) Properties of lime-metakolin mortars for the restoration of historic masonries. Applied Clay Science, 53, 15-19.

Almond D.P. \& Bowen C.R. (2004) Anomalous power law dispersions in ac conductivity and permittivity shown to be characteristics of microstructural electrical networks. Physical Review Letters, 92, 157601.

Andersen M.D., Jakobsen H.J. \& Skibsted J. (2003) Incorporation of aluminum in the calcium silicate hydrate (c-s-h) of hydrated portland cements: A high-eld ${ }^{27} \mathrm{Al}$ and ${ }^{29} \mathrm{Si}$ MAS NMR investigation. Inorganic Chemistry, 42, 2280-2287.

Apih T., Lahajnar G., Sepe A., Blinc R., Milia F., Cvelbar R., Emri I., Gusev B. \& Titova L. (2001) Proton spin-lattice relaxation study of the hydration of self-stressed expansive cement. Cement and Concrete Research, 31, 263-269.

Bakolas A., Aggelakopoulou E., Moropoulou A. \& Anagnostopoulou S. (2006) Evaluation of pozzolanic activity and physicomechanical characteristics in metakaolin-lime pastes. Journal of Thermal Analysis and Calorimetry, 84, 157-163.

Ball R., Allen G., Starrs G. \& McCarter W. (2011) Impedance spectroscopy measurements to study physiochemical processes in lime-based composites. Applied Physics A, 105, 739-751.

Ball R.J., Pesce G.L., Bowen C.R. \& Allen G.C. (2012) Characterisation of lime/metakaolin paste using impedance spectroscopy. Pp. 487-494 in: Novel and Non-Conventional Materials and Technologies for Sustainability (Y. Xiao, Z. Li, R.Wang, B. Shan \& K. Ghavami, editors). Key Engineering Materials, 517.

Beyea S., Balcom B., Bremner T., Prado P., Green D., Armstrong R. \& Grattan-Bellew P. (1998) Magnetic resonance imaging and moisture content proles of drying concrete. Cement and Concrete Research, 28, 453-463.

Boguszynska J., Brown M.C., McDonald P.J., Mitchell J., Mulheron M., Tritt-Goc J. \& Verganelakis D.A. (2005) Magnetic resonance studies of cement based materials in inhomogeneous magnetic fields. Cement and Concrete Research, 35, 2033-2040.

Cabrera J. \& Rojas M.F. (2001) Mechanism of hydration of the metakaolin-lime-water system. Cement and Concrete Research, 31, 177-182.

Cano-Barrita P. d. J., Marble A., Balcom B., Garcia J., Masthikin I., Thomas M. \& Bremner T. (2009) Embedded NMR sensors to monitor evaporable water loss caused by hydration and drying in portland cement mortar. Cement and Concrete Research, 39, 324-328.

Cong X. \& Kirkpatrick R. (1996) ${ }^{29} \mathrm{Si}$ and ${ }^{17} \mathrm{O}$ NMR investigation of the structure of some crystalline calcium silicate hydrates. Advanced Cement Based Materials, 3, 133-143.

Damidot D. \& Glasser F. (1995) Investigation of the $\mathrm{CaO}-\mathrm{Al}_{2} \mathrm{O}_{3}-\mathrm{SiO}_{2}-\mathrm{H}_{2} \mathrm{O}$ system at $25^{\circ} \mathrm{C}$ by thermodinamicd calculations. Cement and Concrete Research, 25, 22-28.

Edwards D. (2009) Sustainable Lime Mortars. PhD thesis, Interface Analysis Centre, University of Bristol, UK.

European Committe for Standardization (2010) Building lime part 1: Denition, speciations and conformity criteria.

Frias M. \& Cabrera J. (2000) Pore size distribution and degree of hydration of metakaolin-cement pastes. Cement and Concrete Research, 30, 561-569.

Frias M., Martinez-Ramirez S., Blasco T. \& Rodriguez M.F. (2013) Evolution of mineralogical phases by ${ }^{27} \mathrm{Al}$ and ${ }^{29} \mathrm{Si} \mathrm{NMR}$ in MK-Ca $(\mathrm{OH})_{2}$ system cured at $60^{\circ} \mathrm{C}$. Journal of the American Ceramic Society, 96, $2306-2310$.

Khatib J. \& Wild S. (1996) Pore size distribution of metakaolin paste. Cement and Concrete Research, 26, 1545-1553.

Liu Q., Spears D. \& Liu Q. (2001) MAS NMR study of surface-modified calcined kaolin. Applied Clay Science, 19, 89-94.

Martinez-Ramirez S. \& Frias M. (2011) Micro-raman 
study of stable and metastable phases in metakaolin/ $\mathrm{Ca}(\mathrm{OH})_{2}$ system cured at $60^{\circ} \mathrm{C}$. Applied Clay Science, 51, 283-286.

Moropoulou A., Bakolas A. \& Aggelakopoulou E. (2004) Evaluation of pozzolanic activity of natural and articial pozzolans by thermal analysis. Thermochimica Acta, 420, 135-140.

Morsy M., Alsayed S. \& Salloum Y. (2012) Development of eco-friendly binder using metakaolin-fly ash lime-anhydrous gypsum. Construction and Building Materials, 35, 772-777.

Pesce G. (2006) Optimization of the thermal activation of kaolin used as hydraulic additive for air lime. Influence of partial pressure of water on the reactivity of metakaolin. Ph.D Thesis, Department of Construction, Town Planning and Materials Engineering of the University of Genoa, Italy.

Pesce G. \& Ricci R. (2008) The use of metakaolinite as a hydraulic agent of aerial lime plasters and mortars. the case study of Genoa (Italy). In: Proceedings of the $1^{\text {st }}$ Historical Mortars Conference - HMC08 Characterization, Diagnosis, Conservation, Repair and Compatibility. RILEM.

Rashad A.M. (2013) Metakaolin as cementitious material: History, scours, production and composition. A comprehensive overview. Construction and Building Materials, 41, 303-318.

Rocha J. \& Klinowski J. (1990a) ${ }^{29} \mathrm{Si}$ and ${ }^{27} \mathrm{Al}$ MagicAngle-Spinning NMR studies of the thermal transformation of kaolinite. Physics and Chemistry of Minerals, 17, 179-186.

Rocha J. \& Klinowski J. (1990b) Kaolinite as a Convenient Standard for Setting the HartmannHahn Match for 29Si CP/MAS NMR of Silicates. Journal of Magnetic Resonance, 90, 567-568

Rojas M.F. \& de Roja M.S. (2003) The effect of high curing temperature on the reaction kinetics in $\mathrm{mk} /$ lime and mk-blended cement matrices at $60^{\circ} \mathrm{C}$. Cement and Concrete Research, 33, 643-649.

Zendri E., Lucchini V., Biscontin G. \& Morabito Z.M. (2004) Interaction between clay and lime in cocciopesto mortars: a study by ${ }^{29} \mathrm{Si}$ MAS spectroscopy. Applied Clay Science, 25, 1-7. 